\title{
Analysis of adherence, biofilm formation and
cytotoxicity suggests a greater virulence potential of
Gardnerella vaginalis relative to other bacterial-
vaginosis-associated anaerobes \\ Correspondence \\ Kimberly K. Jefferson \\ kkjefferson@vcu.edu \\ Received 1 September 2009 \\ Revised 4 November 2009 \\ Accepted 9 November 2009

\author{
Jennifer L. Patterson, ${ }^{1}$ Annica Stull-Lane, ${ }^{1}$ Philippe H. Girerd ${ }^{2}$ \\ and Kimberly K. Jefferson ${ }^{1}$ \\ 1 Department of Microbiology and Immunology, PO Box 980678, Virginia Commonwealth University, \\ Richmond, VA 23928, USA \\ ${ }^{2}$ Department of Obstetrics and Gynecology, Virginia Commonwealth University, Richmond, VA, USA
}

\section{INTRODUCTION}

Bacterial vaginosis (BV) is the most prevalent vaginal disorder in women of reproductive age, affecting 10-20\% of Caucasian women, and 30-50\% of African American women, although estimates of its prevalence depend on the population studied (Eschenbach, 1993; Sobel, 2000). The normal healthy vagina is populated mainly by hydrogenperoxide-producing lactobacilli that inhibit the growth of other vaginal flora (Eschenbach et al., 1989). BV is characterized by a loss of these protective lactobacilli, an increase in vaginal $\mathrm{pH}$ to $>4.5$, and the proliferation of a variety of anaerobic species. Symptoms of BV can include a thin greyish-white vaginal discharge with a foul odour, and mild irritation. Of more concern is that BV is associated with serious disorders, such as pelvic inflammatory disease (Sobel, 2000; Larsson et al., 2005) and adverse pregnancy outcomes, such as preterm delivery, low birth weight and post-partum endometritis. BV also increases the risk of

Abbreviation: BV, bacterial vaginosis. male-to-female, and female-to-male, HIV transmission (Schmid et al., 2000).

Gardnerella vaginalis is present in up to $95 \%$ of cases of BV (Catlin, 1992; Marrazzo et al., 2008); however, with the advancement of molecular tools, it has been shown that the numbers and diversity of anaerobes associated with BV are high (Oakley et al., 2008). One study has found that pure cultures of G. vaginalis do not always cause BV, and that the organism can occur, albeit in low numbers, in healthy women (Gardner \& Dukes, 1955; Fredricks et al., 2007). Together, these findings cast doubt on the role of $G$. vaginalis in the pathogenesis of $\mathrm{BV}$. Recently, the term functional equivalent pathogen/pathogroup has been proposed for polymicrobial infections in which no one species alone is capable of causing disease, but rather the synergistic effects of the consortium give rise to the pathophysiology (Dowd et al., 2008). Inarguably, the vagina is colonized by numerous anaerobic bacteria during $\mathrm{BV}$, but whether the symptoms and the syndrome are a consequence of the multispecies consortium, or whether 
there is a key species in each case that precipitates the disorder, has been a matter of debate for decades. A followup study to the report that G. vaginalis in pure culture does not reliably cause BV found that fresh cultures initiated the infection more frequently (Criswell et al., 1969); this suggests that, under conditions that foster expression of virulence determinants, G. vaginalis might have greater pathogenic potential. Furthermore, recent studies have indicated that $G$. vaginalis is equipped with a number of virulence properties, and consequently the idea that it is the aetiological agent of BV is being revisited (Swidsinski et al., 2005; Gelber et al., 2008). Swidsinski et al. (2005) have recently shown that G. vaginalis is able to form an adherent biofilm on the vaginal epithelium of women with BV. The biofilm incorporates other bacterial groups into its layers, suggesting that it may enable other anaerobes to colonize the vagina. G. vaginalis also produces the toxin vaginolysin, which is a member of the cholesteroldependent family of pore-forming toxins that lyses human red blood cells and vaginal epithelial cells (Gelber et al., 2008). It has been hypothesized that vaginolysin is involved in the pathogenesis of BV. G. vaginalis can also adhere well to vaginal epithelial cells, and it attaches equally well to exfoliated vaginal epithelial cells and tissue culture cells (Sobel et al., 1981; Scott \& Smyth, 1987). Finally, not only does G. vaginalis have numerous virulence factors that could contribute to the pathogenesis of $\mathrm{BV}$, it has also been implicated as the sole aetiological agent of infections outside of the reproductive tract. There have been reports of $G$. vaginalis as the causative agent of vertebral osteomyelitis and discitis, retinal vasculitis, acute hip arthritis and bacteraemia (Graham et al., 2009; Neri et al., 2009; Sivadon-Tardy et al., 2009; Lagace-Wiens et al., 2008). Together, these virulence properties suggest that $G$. vaginalis may be the key player in the pathogenesis of BV.

Many of the bacterial species associated with BV have evolved to exist in humans only, and consequently a reliable animal model for BV does not exist. This has stymied efforts to tease out the pathogenesis of BV; hence, studies of the aetiology of BV are lacking. Reports of the frequency with which different species are isolated exist, but they point only to association, and not cause. For example, Atopobium vaginae is frequently isolated from cases of $\mathrm{BV}$, and a study has indicated its potential to induce an inflammatory response, but there has not been a demonstration that it is equipped with specific virulence factors (Libby et al., 2008). In an effort to begin to unravel this aetiological mystery, we designed a simple model to test adherence to vaginal epithelial cells, and used established models to analyse the biofilm-forming capacity and cytotoxicity of $G$. vaginalis and a number of additional BV isolates, including $A$. vaginae, Prevotella bivia, Mobiluncus mulieris, a Veillonella sp., a Peptostreptococcus sp., a Peptoniphilus sp. and Fusobacterium nucleatum (Oakley et al., 2008; Nikolaitchouk et al., 2008; Verstraelen et al., 2004).

\section{METHODS}

Strains and culture conditions. All media components were obtained from Becton Dickinson, unless otherwise noted. Bacterial strains used in this study, references to their association with BV, and the source of the strains, are listed in Table 1. The strains were purchased from ATCC, isolated from confirmed cases of BV (confirmed by Amsel criteria and Nugent score; Holmes et al., 1981) at Brigham and Women's Hospital, Boston, MA, USA (Onderdonk et al., 2003), or isolated as part of this study from Virginia Commonwealth University (VCU) Women's Health Clinic. Strains from the VCU Women's Health Clinic were isolated from vaginal swab specimens taken from women diagnosed with BV by the Amsel criteria. Individual colonies were isolated on brucella blood agar plates (Oxyrase), and cultured in supplemented brain heart infusion broth [sBHI; brain heart infusion broth (Difco) containing $2 \%(\mathrm{w} / \mathrm{v})$ gelatin, $0.5 \%$ yeast extract, $0.1 \%$ starch, and $0.1 \%$ glucose]. Genomic DNA was isolated using the DNeasy Blood and Tissue kit (Qiagen), and amplified by PCR using universal primers for the 16S rRNA gene (UnivFWD 5'-AGAGTTTGATCCTGGCTCAG-

Table 1. Strains used in this study

\begin{tabular}{|c|c|c|}
\hline Organism & Strain and source & Reference to involvement in BV \\
\hline M. mulieris & BV 26-9† & $\begin{array}{l}\text { Menard et al. (2008), Oakley et al. (2008), Fredricks et al. (2005), Marrazzo et al. } \\
\text { (2008) }\end{array}$ \\
\hline Veillonella sp. & $715 B V A \ddagger$ & Oakley et al. (2008), Lefevre et al. (1985), Biagi et al. (2009) \\
\hline Peptostreptococcus sp. & 715BVC $\ddagger$ & Oakley et al. (2008), Marrazzo et al. (2008) \\
\hline Peptoniphilus sp. & 718BVA $\ddagger$ & Fredricks et al. (2005), Marrazzo et al. (2008) \\
\hline F. nucleatum & 718BVC $\ddagger$ & Oakley et al. (2008) \\
\hline
\end{tabular}

*Brigham and Women's Hospital.

$\dagger$ American Type Culture Collection.

łVCU Women's Health Clinic. 
3', and UnivREV 5'-GGACTACCAGGGTATCTAAT-3'). PCR products were sequenced at the VCU Nucleic Acids Core Facility, and species were identified by a $98 \%$, or greater, identity using BLASTN (http://blast.ncbi.nlm.nih.gov/Blast.cgi) All cultures were grown under anaerobic conditions, in approximately $10 \% \mathrm{CO}_{2}$, with the use of the AnaeroPack system (Mitsubishi Gas Chemical Company). For subsequent experiments, cultures were grown in sBHI supplemented with $1 \%$ glucose (sBHIG).

Cell line. ME-180 vaginal epithelial cells (ATCC) were cultured at $37{ }^{\circ} \mathrm{C}$, in $5 \% \mathrm{CO}_{2}$, in McCoy's $5 \mathrm{~A}$ medium (Quality Biological) supplemented with $10 \% \mathrm{FBS}$ and $1 \mathrm{IU}$ penicillin/streptomycin $\mathrm{ml}^{-1}$ (MediaTech).

Confocal microscopic adherence assay. ME-180 epithelial cells were seeded into six-well tissue culture plates (Greiner) at a density of $1.5 \times 10^{5}$ cells per well, and incubated for $72 \mathrm{~h}$ or until a monolayer of cells had formed. The growth medium was removed, and the cell monolayer was washed twice with sterile PBS, and stained with Vybrant DIL membrane stain $\left(2.5 \mu \mathrm{ml}^{-1}\right.$ per well; Invitrogen) for $30 \mathrm{~min}$ at $37{ }^{\circ} \mathrm{C}$, in $5 \% \mathrm{CO}_{2}$. Following incubation, the monolayers were washed twice with sterile PBS to remove excess stain. Overnight cultures of the various bacterial strains were standardized to an $\mathrm{OD}_{600}$ of 0.150 using a NanoDrop 1000 (Thermo Scientific), and $2 \mathrm{ml}$ of each culture was centrifuged to collect the cells. Bacteria were washed twice with $1 \mathrm{ml}$ sterile PBS, and stained with $5 \mu \mathrm{l}$ BacLight green bacterial stain (Invitrogen) in $1 \mathrm{ml}$ PBS. The bacterial cells were incubated in the dark for $30 \mathrm{~min}$ at $37^{\circ} \mathrm{C}$, and washed twice with $1 \mathrm{ml}$ sterile PBS to remove excess stain. Stained bacteria $\left(1 \times 10^{7}\right.$ cells in $0.5 \mathrm{ml}$ PBS) were added to each well containing ME-180 cells. The plates were centrifuged at 700 r.p.m. $(18 \mathrm{~g})$ for $2 \mathrm{~min}$ to maximize the contact between the bacteria and the cells. Time-course assays indicated that adherence of bacteria to ME- 180 cells did not increase after 15 min of contact (data not shown); therefore, covered plates were incubated for $15 \mathrm{~min}$ at $37^{\circ} \mathrm{C}$ in $5 \% \mathrm{CO}_{2}$. After exposure to $G$. vaginalis at $37{ }^{\circ} \mathrm{C}$ for $15 \mathrm{~min}$, the $\mathrm{ME}-180$ cells began to exhibit cytopathogenic changes. Therefore, $G$. vaginalis was incubated at $10{ }^{\circ} \mathrm{C}$ to prevent cytotoxicity; these conditions did not affect binding of any of the other species. Finally, the wells were washed vigorously twice with sterile PBS to remove non-adherent bacteria, and the wells were analysed by confocal microscopy using a muliphoton confocal scanning laser microscope (Zeiss LSM 510; Microscopy Core Facility, Neuroscience Department, VCU).

Adherence assays were repeated three times on separate days, with three fields of view assessed each time.

Biofilm assay. Biofilms were grown using 96-well Corning Cell Bind Plates (Corning Glass Works). Overnight cultures of G. vaginalis or BV-associated anaerobes were diluted 1:10 with fresh sBHI, and individual wells of a sterile 96-well polystyrene tissue culture plate were inoculated with $0.2 \mathrm{ml}$ dilute culture. The tissue culture plates were incubated for $24-72 \mathrm{~h}$ at $37^{\circ} \mathrm{C}$, under anaerobic conditions. Growth was analysed using a 96-well plate spectrophotometer with a $595 \mathrm{~nm}$ filter (BioTek 800 plate reader). Spent medium was removed, wells were washed with $200 \mu \mathrm{l}$ PBS to remove non-adherent bacteria, and the plates were air-dried for $1 \mathrm{~h}$. Biofilms were stained with $200 \mu \mathrm{l}$ safranin for $1 \mathrm{~min}$, then wells were washed gently to remove the safranin, and the plates were air-dried. After the biofilms had been visually analysed and imaged using a flatbed scanner, the safranin was solubilized with $200 \mu \mathrm{l} 33 \%(\mathrm{v} / \mathrm{v})$ acetic acid per well. For quantitative results, the $A_{562}$ of the solubilized safranin was measured, using the 96-well plate reader.

Cytotoxicity assay. ME-180 epithelial cells were seeded into a 96well tissue culture plate at a density of $3.0 \times 10^{4}$ cells per well. After
$72 \mathrm{~h}$, or when a monolayer of cells had formed, the medium was removed, and a suspension containing approximately $1 \times 10^{6}$ bacteria in PBS was added to each well. The monolayers were analysed for cytotoxicity by light microscopy every hour for $4 \mathrm{~h}$. After the monolayers had been analysed for $4 \mathrm{~h}$, and given a cytotoxicity score, the bacteria were removed by pipetting off the liquid from each well, and microscopic images of each well were taken with an Olympus CK2 microscope.

\section{RESULTS}

\section{G. vaginalis and Peptoniphilus adhered to vaginal epithelial cells}

We analysed the ability of BV isolates G. vaginalis, A. vaginae, M. mulieris, $P$. bivia, Veillonella sp., Peptostreptococcus sp., Peptoniphilus sp. and F. nucleatum (Table 1) to bind to ME-180 vaginal epithelial cells. Overnight cultures were standardized to ensure that equal numbers of bacteria were present in each culture, and the bacteria were stained with a green fluorophore, and allowed to interact with a monolayer of red fluorescentlabelled ME-180 vaginal epithelial cells for 15 min before washing to remove non-adherent bacteria. Fig. 1 shows representative confocal microscopic images of red ME- 180 cells and green bacteria. Both G. vaginalis and Peptoniphilus sp. exhibited considerable adherence. Peptoniphilus sp. adhered more homogeneously to the ME-180 cells, whereas G. vaginalis, which is very aggregative, adhered as large clusters. As shown in Fig. 1, F. nucleatum and A. vaginae exhibited some adherence to the epithelial cells, although to a significantly lesser degree than that shown by $G$. vaginalis or Peptoniphilus sp.; M. mulieris, P. bivia strain 715BVD, P. bivia strain 29303 (results not shown), Veillonella sp. and Peptostreptococcus sp. were unable to adhere to the vaginal epithelial cells under the conditions used. Table 2 lists the adherence scores for each species after incubation with the monolayer for $15 \mathrm{~min}$; the scores correlate with the confocal microscopy images. Each experiment was repeated three times, and produced similar results each time.

\section{G. vaginalis formed a significantly thicker biofilm than other BV-associated anaerobes}

Biofilm assays were performed to analyse the biofilmforming potential of $G$. vaginalis and other BV-associated anaerobes. When cultured overnight on tissue-culturetreated polystyrene, G. vaginalis strains 5-1, 465 and 101-1 produced thick tenacious biofilms (Fig. 2). F. nucleatum was able to produce a moderately fluffy biofilm that was partially dislodged by washing. The ease with which $F$. nucleatum biofilms were dislodged by washing is reflected by the large standard deviation in Fig. 2(b). The other anaerobes tested - A. vaginae, M. mulieris, P. bivia, Veillonella, Peptostreptococcus and Peptoniphilus - demonstrated significantly lower biofilm formation relative to $G$. vaginalis (Student's $t$-test, $P<0.0001$ ). 

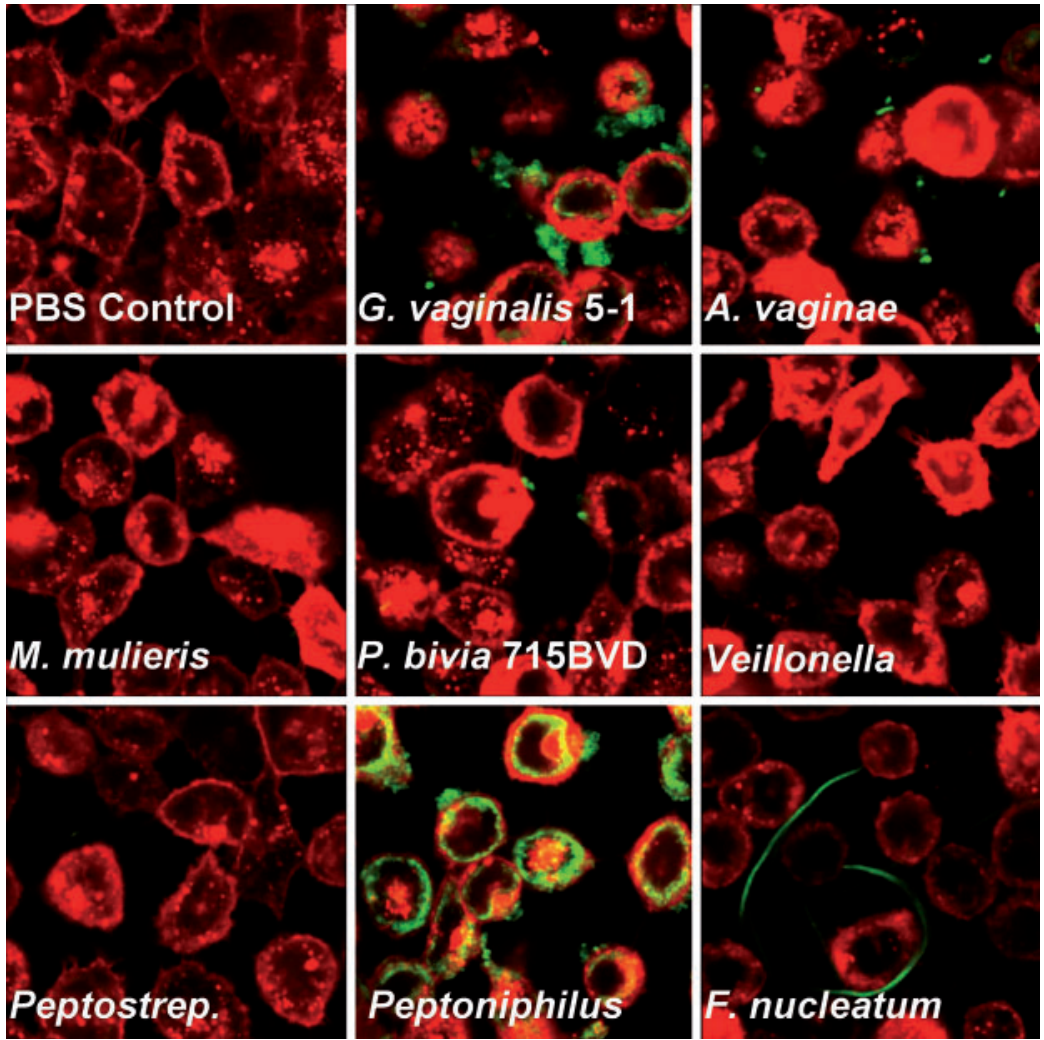

Fig. 1. Adherence of $G$. vaginalis BV-associated anaerobes to vaginal epithelial cells. Bacteria were grown anaerobically in $\mathrm{SBHIG}$ at $37{ }^{\circ} \mathrm{C}$ for $24 \mathrm{~h}$. Bacteria (green) cultures were standardized to ensure equal numbers, and added to vaginal epithelial cells (red). After incubation for $15 \mathrm{~min}$, non-adherent bacteria were removed by washing. Qualitative estimates of adherence were ascertained by confocal microscopy. P. bivia strain 29303 (not shown) did not exhibit adherence.

\section{Only G. vaginalis strains were cytotoxic for vaginal epithelial cells}

G. vaginalis strains and BV-associated anaerobes were tested for their ability to cause cell rounding and lysis of ME-180 vaginal epithelial cells. Equal numbers of each bacterial species were added to a confluent monolayer of ME-180 vaginal epithelial cells. Cytotoxicity scores (Table 2) and microscopic images (Fig. 3) of the monolayer were recorded after $4 \mathrm{~h}$. As shown in Fig. 3, only the G. vaginalis strains induced rounding and cell death of the ME-180 cells. All of the $G$. vaginalis strains were scored as 5 on the cytotoxicity scale; this indicated complete lysis of the monolayer within $4 \mathrm{~h}$. All other anaerobes tested lacked detectable cytotoxic activity, and were scored as 0 on the cytotoxicity scale. Each experiment was repeated three times, and produced similar results each time.

\section{DISCUSSION}

Despite the fact that $G$. vaginalis can be isolated in greater than $95 \%$ of cases of BV, a study with healthy human volunteers has indicated that pure cultures of the bacteria do not always cause BV, and this has cast perpetual doubt on its pathogenic potential (Gardner \& Dukes, 1955; Criswell et al., 1969). However, the link between vaginolysin and BV, along with studies showing G. vaginalis as the predominant species in biofilms that form on the vaginal epithelium during $\mathrm{BV}$, suggest that the role of this species as a pathogen should be readdressed.

As animal models for BV are lacking, we designed a series of in vitro experiments to compare the relative virulence capacities of $G$. vaginalis and other BV-associated anaerobes. Adherence is a key first step in pathogenesis, as a potential pathogen must first adhere to host tissues in order to avoid clearance by host defence mechanisms, such as the mucociliary escalator, urine flow, and the flow of vaginal secretions. Furthermore, adherence is the first step in the formation of a biofilm, and the capacity to form a biofilm on polystyrene is irrelevant to pathogenesis unless the bacteria can first adhere to the vaginal epithelium. We therefore analysed the ability of BV-associated anaerobes to adhere to vaginal epithelial cells in tissue culture. Only $G$. vaginalis and Peptoniphilus sp. adhered avidly to ME-180 vaginal epithelial cells. G. vaginalis tended to form clumps of bacteria that adhered to cells, while Peptoniphilus sp. was more evenly distributed around the borders of the epithelial cells. Our data confirm the results of previous studies that have shown that G. vaginalis adheres to McCoy cells and human red blood cells (Scott et al., 1989). Peptoniphilus sp. has been recently named, and is associated with persistent cases of BV; Marrazzo et al., (2008) have isolated the organism from $36 \%$ of persistent cases of BV. This is believed to be the first study to demonstrate the robust adherence of Peptoniphilus sp. to vaginal epithelial cells; this is an interesting and potentially important 
Table 2. Adherence and cytotoxicity scores of the bacterial strains

Experiments were repeated three times, and produced similar results each time.

\begin{tabular}{|lcc|}
\hline Strain & $\begin{array}{c}\text { Cytotoxicity } \\
\text { score }^{\star}\end{array}$ & $\begin{array}{c}\text { Adherence } \\
\text { score } \dagger\end{array}$ \\
\hline PBS control & 0 & - \\
G. vaginalis $5-1$ & 5 & +++ \\
G. vaginalis $101-1$ & 5 & +++ \\
G. vaginalis 465 & 5 & +++ \\
A. vaginae FA & 0 & ++ \\
M. mulieris BV $26-9$ & 0 & \pm \\
P. bivia 29303 & 0 & \pm \\
P. bivia 715BVD & 0 & - \\
Veillonella sp. $715 \mathrm{BVA}$ & 0 & - \\
Peptostreptococcus sp. & 0 & +++ \\
715BVC & & + \\
Peptoniphilus sp. & 0 & \\
F. nucleatum $718 \mathrm{BVC}$ & 0 & \\
& & \\
\hline
\end{tabular}

${ }^{*}$ Cytotoxicity was scored as follows: 0 , no difference between the experimental well and the control; $1,<25 \%$ cells were rounded; 2, 25-50\% cells were rounded; $3,>50 \%$ cells were rounded; $4,>50 \%$ cells were rounded, with partial disruption of the monolayer; 5 , complete disruption/absence of the monolayer.

$\dagger$ Adherence was scored as follows: - , no adherent bacteria were observed in any field of view on all days tested;,$\pm<25 \%$ of ME- 180 cells had bacteria attached in any field of view on 1 or 2 days, but the result was not repeatable for all three experiments;,$+<25 \%$ of ME180 cells had bacteria attached in all fields of view on all days tested; ,$++ \geqslant 25 \%$ to $<75 \%$ of ME- 180 cells had bacteria attached in all fields of view on all days tested;,$+++ \geqslant 75 \%$ to $100 \%$ of ME- 180 cells had bacteria attached in all fields of view on all days tested.

observation. Perhaps Peptoniphilus sp. associates with G. vaginalis during cases of $\mathrm{BV}$, and leads to the pathogenesis seen with the disorder; this hypothesis warrants more research into the role that Peptoniphilus sp. plays in the pathogenesis of BV. A. vaginae and F. nucleatum exhibited moderate adherence only, and adherent M. mulieris, $P$. bivia and Peptostreptococcus were not detected. The process of dental biofilm formation is initiated by bacterial species, such as streptococci and actinomycetes, that have affinity for the tooth pellicle. These species are referred to as initial colonizers. Other bacterial species adhere to the initial colonizers, and this leads to the development of a complex biofilm community composed of a large variety of species, many of which are unable to adhere to teeth on their own. Specifically, F. nucleatum expresses receptors that adhere to a large variety of other bacterial species, and it acts as a bridge between early and late colonizers (Kolenbrander et al., 2002; Periasamy \& Kolenbrander, 2009). Because G. vaginalis is able to adhere to, and form a biofilm on, vaginal epithelia, it is plausible that it is an initial colonizer that paves the way for additional species with low innate pathogenic potential to become established in the vagina.
Next, we analysed biofilm formation. Biofilm formation is an important virulence factor because it confers heightened antibiotic tolerance and resistance to host immune defences. Due to the fact that biofilm bacteria are not effectively cleared by the immune system, or completely killed by antibiotics, biofilm-related infections tend to be chronic and/or relapsing. BV tends to be a smouldering infection with a high rate of relapse or recurrence. Indeed, direct evidence from the microscopic analysis of vaginal biopsies of women with BV has revealed the presence of a bacterial biofilm on the vaginal epithelium (Swidsinski et al., 2005). A follow-up study revealed that metronidazole therapy failed to clear the biofilm, and suggested that this was related to relapse (Swidsinski et al., 2008). These studies have revealed biofilm formation as an important virulence determinant in BV. In our in vitro assay, $G$. vaginalis formed a moderate or strong biofilm, depending on the strain, and F. nucleatum formed a moderate biofilm that was easily dislodged. None of the other BV-associated anaerobes was able to form a significant biofilm.

The production of a cytolysin by G. vaginalis was first reported in 1990, but it has only recently been named vaginolysin, and characterized as a pore-forming cytotoxin that utilizes the complement regulatory molecule CD59 to activate the epithelial p38-mitogen-activated protein kinase pathway in human epithelial cells, leading to cell death (Gelber et al., 2008; Rottini et al., 1990). IgA antibodies against vaginolysin have been linked to the mucosal immune response during $\mathrm{BV}$, further supporting the role of vaginolysin in BV pathogenesis (Cauci et al., 2002). We analysed the relative cytotoxic activity levels of the BVassociated anaerobes, and found that only G. vaginalis was able to induce rounding and lysis of ME-180 vaginal epithelial cells. The other BV-associated species did not elicit detectable cytopathological changes, even when the bacteria were incubated with the ME-180 cells overnight.

Our study did not include all of the bacterial species that have been found to be associated with cases of BV. BV is a polymicrobial disorder, and the diversity of species associated with the disorder continues to increase as detection methods, such as $16 \mathrm{~S}$ pyrosequencing, improve. Because of the large number of candidates, and because many bacteria found to be associated with BV are unculturable, we focused instead on a relatively small number of commonly isolated species. The in vitro model of adherence used in this study is limited by the fact that cell monolayers of ME-180 cells are not polarized, as are vaginal epithelial cells in vivo. The assay for biofilm formation was limited by the fact that the growth medium did not contain all of the factors found in vivo, and some in vivo cues may turn on expression of biofilm-related genes. However, these limitations aside, in vitro models can be very informative, and are key to furthering our understanding of $\mathrm{BV}$, as the lack of a tractable animal model for $\mathrm{BV}$ has thwarted efforts to understand the aetiology of this common and important health concern of women. While it is plausible that our in vitro study did not test for 
(a)

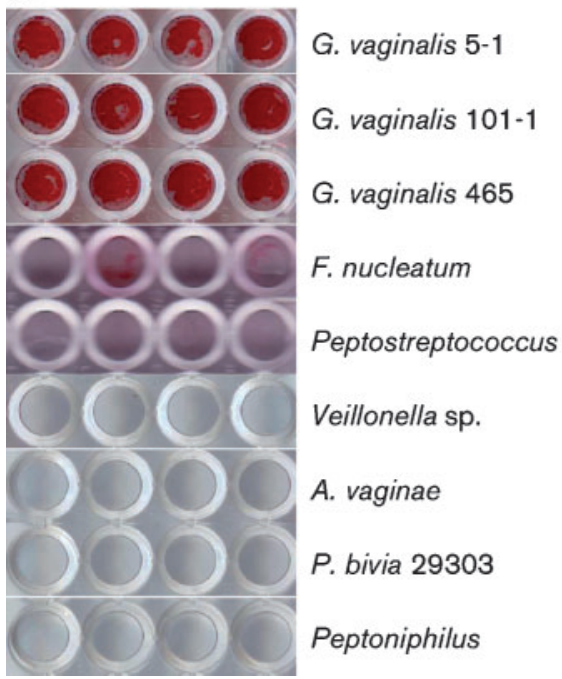

(b)

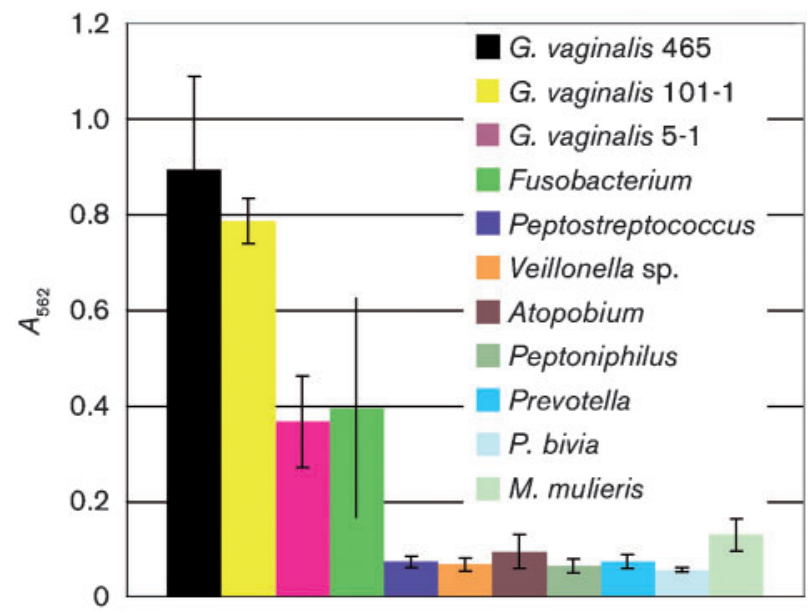

Fig. 2. Biofilm formation of $G$. vaginalis strains and various BV-associated anaerobes. (a) Bacteria were grown anaerobically in sBHIG at $37{ }^{\circ} \mathrm{C}$ for $24 \mathrm{~h}$. Non-adherent cells were removed from the wells, and the adherent bacteria were stained with safranin. $\mathrm{OD}_{595}$ readings were determined to ensure similar growth of each species. Experiments were repeated three times, and produced similar results each time; representative images are shown. (b) Quantitative assessment of the biofilm-forming capacities were made by dissolving the safranin stain in $33 \%$ acetic acid and measuring $O D_{562}$. Eight technical replicates and 3 biological replicates $(n=24)$ were performed on each strain and the absorbance readings were averaged. Error bars represent standard deviations. P. bivia strain BVD is not shown but similar to P. bivia strain 29303 , it did not exhibit biofilm formation.
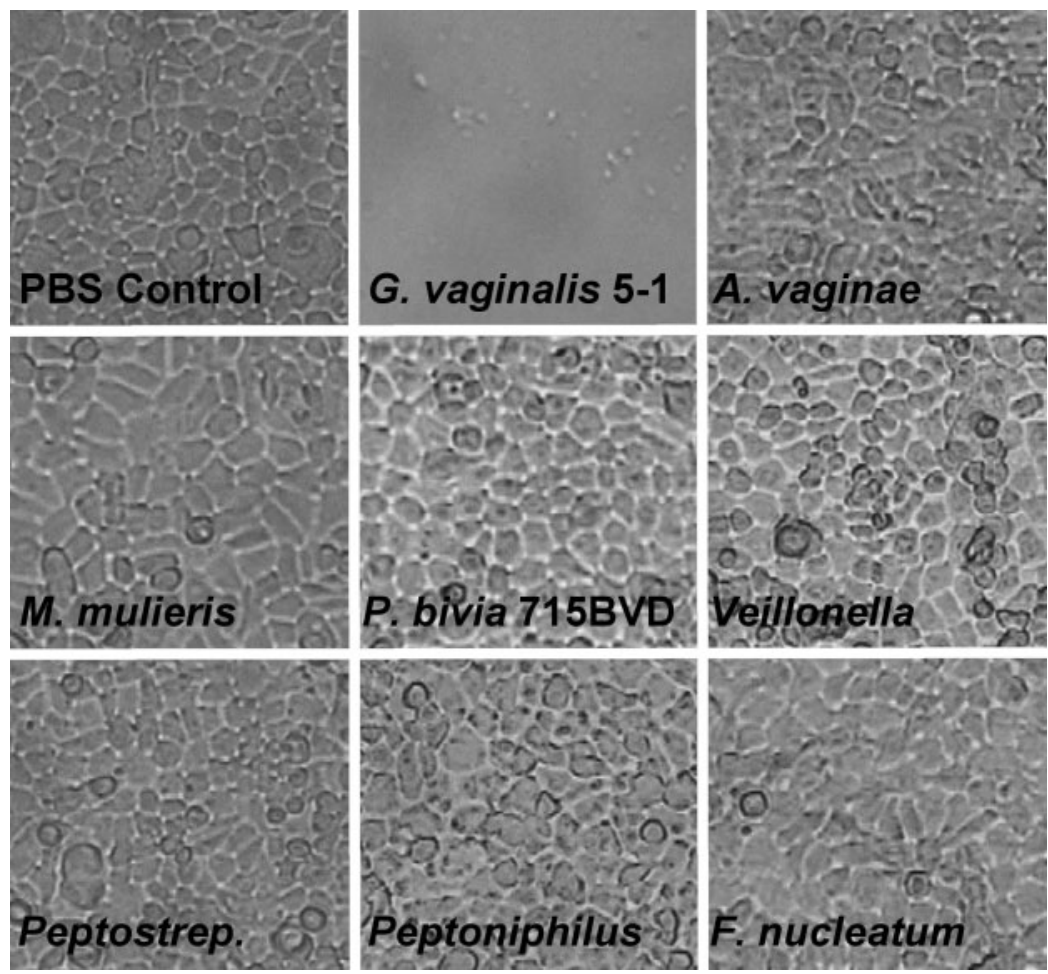

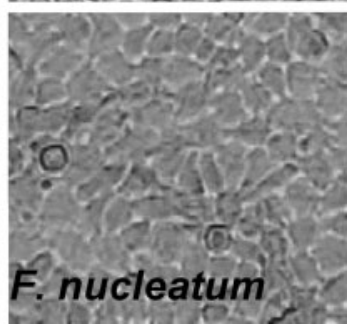

Fig. 3. Cytotoxic changes of vaginal epithelial cell monolayers challenged with $G$. vaginalis strains and various BV-associated anaerobes. Bacteria were grown anaerobically in $\mathrm{SBHIG}$ at $37{ }^{\circ} \mathrm{C}$ for $24 \mathrm{~h}$, and cultures were standardized to ensure equal numbers. Bacteria were added to vaginal epithelial cells, and incubated for $4 \mathrm{~h}$. Light microscopy images were taken after incubation for $4 \mathrm{~h}$. P. bivia strain BVD (not shown) did not exhibit cytotoxicity, and produced results that were similar to those of $P$. bivia strain 29303. 
virulence properties that play an important role in BV pathogenesis, or that the conditions used did not allow for full expression of certain virulence factors, our results are suggestive of a higher innate virulence potential for $G$. vaginalis relative to other $\mathrm{BV}$-associated species. While a number of the BV-associated anaerobes tested in this study had one of the three virulence properties tested, only $G$. vaginalis displayed robust cytotoxicity, strong adherence to vaginal epithelial cells, and a propensity to form a dense biofilm; these findings suggest a key role for G. vaginalis in BV pathogenesis. Additional virulence factors produced by G. vaginalis include sialidase and prolidase, which are two hydrolytic enzymes that may have a role in degrading several key mucosal protective factors, such as mucins, as well as contributing to exfoliation and detachment of vaginal epithelial cells (Cauci et al., 2008). In sum, there is strong evidence that $G$. vaginalis does possess innate pathogenic potential. Other $\mathrm{BV}$-associated anaerobes might have virulence factors that have not yet been described, or they may be more pathogenic in the presence of other species. It is also likely that the primary aetiological agent of $\mathrm{BV}$, if there is one, varies on a caseby-case basis. However, this study suggests that, due to its collection of virulence factors, it is likely that G. vaginalis has a pathogenic capacity, and could be the key agent in certain cases of BV.

\section{ACKNOWLEDGEMENTS}

Microscopy was performed at the VCU Department of Anatomy and Neurobiology Microscopy facility, supported, in part, with funding from NIH-NINDS Center core grant 5P30NS047463-02. At VCU, we are grateful to Drs Guy and Francine Cabral for the use of their light microscope camera, to Dr Cynthia Cornelissen for use of her tissue culture facilities, and to Dr Anthony Nicola for the use of his 96-well spectrophotometer. We also thank Dr Andrew Onderdonk, Dr Robin Ross and Mary Delaney for providing us with BV isolates.

\section{REFERENCES}

Biagi, E., Vitali, B., Pugliese, C., Candela, M., Donders, G. G. \& Brigidi, P. (2009). Quantitative variations in the vaginal bacterial population associated with asymptomatic infections: a real-time polymerase chain reaction study. Eur J Clin Microbiol Infect Dis 28, 281-285.

Catlin, B. W. (1992). Gardnerella vaginalis: characterisitics, clinical considerations, and controversies. Clin Microbiol Rev 5, 213-237.

Cauci, S., Driussi, S., Guaschino, S., Isola, M. \& Quadrifoglio, F. (2002). Correlation of local interleukin-1 $\beta$ levels with specific IgA response against Gardnerella vaginalis cytolysin in women with bacterial vaginosis. Am J Reprod Immunol 47, 257-264.

Cauci, S., Culhane, J.F., Di Santolo, M. \& McCollum, K. (2008). Among pregnant women with bacterial vaginosis, the hydrolytic enzymes sialidase and prolidase are positively associated with interleukin-1beta. Am J Obstet Gynecol 198, 132.e1-7.

Criswell, B. S., Ladwig, C. L., Gardner, H. L. \& Dukes, C. D. (1969). Haemophilus vaginalis: vaginitis by inoculation from culture. Obstet Gynecol 33, 195-199.
Dowd, S. E., Wolcott, R. D., Sun, Y., McKeehan, T., Smith, E. \& Rhoads, D. (2008). Polymicrobial nature of chronic diabetic foot ulcer biofilm infections determined using bacterial tag encoded FLX amplicon pyrosequencing (bTEFAP). PLoS One 3, e3326.

Eschenbach, D. A. (1993). History and review of bacterial vaginosis. Am J Obstet Gynecol 169, 441-445.

Eschenbach, D. A., Davick, P. R., Williams, B. L., Klebanoff, S. J., Young-Smith, K., Critchlow, C. M. \& Holmes, K. K. (1989). Prevalence of hydrogen peroxide-producing Lactobacillus species in normal women and women with bacterial vaginosis. J Clin Microbiol 27, 251256.

Fredricks, D. N., Fiedler, T. L. \& Marrazzo, J. M. (2005). Molecular identification of bacteria associated with bacterial vaginosis. $N$ Engl J Med 353, 1899-1911.

Fredricks, D. N., Fiedler, T. L., Thomas, K. K., Oakley, B. B. \& Marrazzo, J. M. (2007). Targeted PCR for detection of vaginal bacteria associated with bacterial vaginosis. J Clin Microbiol 45, 32703276.

Gardner, H. L. \& Dukes, C. D. (1955). Haemophilus vaginalis vaginitis. A newly defined specific infection previously classified 'nonspecific' vaginitis. Am J Obstet Gynecol 60, 962-976.

Gelber, S. E., Aguilar, J. L., Lewis, K. L. \& Ratner, A. J. (2008). Functional and phylogenetic characterization of vaginolysin, the human-specific cytolysin from Gardnerella vaginalis. J Bacteriol 190, 3896-3903.

Graham, S., Howes, C., Dusmuir, R. \& Sandoe, J. (2009). Vertebral osteomyelitis and discitis due to Gardnerella vaginalis. $\mathrm{J}$ Med Microbiol 58, 1382-1384.

Holmes, K. K., Spiegel, C., Amsel, A. R., Eschenbach, D. A., Chen, K. C. \& Totten, P. (1981). Nonspecific vaginosis. Scand J Infect Dis Suppl 26, $110-114$.

Kolenbrander, P. E., Andersen, R. N., Blehert, D. S., Egland, P. G., Foster, J. S. \& Palmer, R. F., Jr (2002). Communication among oral bacteria. Microbiol Mol Biol Rev 66, 486-505.

Lagacé-Wiens, P. R., Ng, B., Reimer, A., Burdz, T., Wiebe, D. \& Bernard, K. (2008). Gardnerella vaginalis bacteremia in a previously healthy man: case report and characterization of the isolate. J Clin Microbiol 46, 804-806.

Larsson, P. G., Bergstrom, M., Forsum, U., Jacobsson, B., Strand, A. \& Wolner-Hanssen, P. (2005). Bacterial vaginosis, transmission, role in genital tract infection and pregnancy outcome: an enigma. APMIS 113, 233-245.

Lefevre, J. C., Jean, M., Averous, S., Viraben, R., Blanc, C., Bauriaud, R. \& Lareng, M. B. (1985). Etiology of bacterial vaginosis (non-specific vaginitis). J Gynecol Obstet Biol Reprod (Paris) 14, 703-708.

Libby, E. K., Pascal, K. E., Mordechai, E., Adelson, M. E. \& Trama, J. P. (2008). Atopobium vaginae triggers an innate immune response in an in vitro model of bacterial vaginosis. Microbes Infect 10, 439-446.

Marrazzo, J. M., Thomas, K. K., Fiedler, T. L., Ringwood, K. \& Fredricks, D. N. (2008). Relationship of specific vaginal bacteria and bacterial vaginosis treatment failure in women who have sex with women. Ann Intern Med 149, 20-28.

Menard, J. P., Fenollar, F., Henry, M., Bretelle, F. \& Raoult, D. (2008). Molecular quantification of Gardnerella vaginalis and Atopobium vaginae loads to predict bacterial vaginosis. Clin Infect Dis 47, 33-43.

Neri, P., Salvolini, S., Giovannini, A. \& Mariotti, C. (2009). Retinal vasculitis associated with asymptomatic Gardnerella vaginalis infection: a new clinical entity. Ocul Immunol Inflamm 17, 36-40.

Nikolaitchouk, N., Andersch, B., Falsen, E., Strombeck, L. \& Mattsby-Baltzer, I. (2008). The lower genital tract microbiota in relation to cytokine-, SLPI- and endotoxin levels: application of 
checkerboard DNA-DNA hybridization (CDH). APMIS 116, $263-$ 277.

Oakley, B. B., Fiedler, T. L., Marrazzo, J. M. \& Fredricks, D. N. (2008), Diversity of human vaginal bacterial communities and associations with clinically defined bacterial vaginosis. Appl Environ Microbiol 74, 4898-4909.

Onderdonk, A. B., Lee, M.-L., Lieberman, E., Delaney, M. L. \& Tuomala, R. E. (2003). Quantitative microbiologic models for preterm delivery. J Clin Microbiol 41, 1073-1079.

Periasamy, S. \& Kolenbrander, P. E. (2009). Aggregatibacter actinomycetemcomitans builds mutualistic biofilm communities in saliva with Fusobacterium nucleatum and Veillonella sp. Infect Immun 77, 3542-3551.

Rottini, G., Dobrina, A., Forgiarini, O., Nardon, E., Amirante, G. A. \& Patriarca, P. (1990). Identification and partial characterization of a cytolytic toxin produced by Gardnerella vaginalis. Infect Immun 58, 3751-3758.

Schmid, G., Markowitz, L., Joesoef, R. \& Koumans, E. (2000). Bacterial vaginosis and HIV infection. Sex Transm Infect 76, 3-4.

Scott, T. G. \& Smyth, C. J. (1987). Hemagglutination and tissue culture adhesion of Gardnerella vaginalis. J Gen Microbiol 133, 19992005.

Scott, T. G., Curran, B. \& Smyth, C. J. (1989). Electron microscopy of adhesive interactions between Gardnerella vaginalis and vaginal epithelial cells, McCoy cells and human red blood cells. J Gen Microbiol 135, 475-480.
Sivadon-Tardy, V., Roux, A. L., Piriou, P., Herrmann, J. L., Gaillard, J. L. \& Rottman, M. (2009). Gardnerella vaginalis acute hip arthritis in a renal transplant recipient. J Clin Microbiol 47, 264-265.

Sobel, J. D. (2000). Bacterial vaginosis. Annu Rev Med 51, 349-356.

Sobel, J. D., Schneider, J., Kaye, D. \& Levison, M. E. (1981). Adherence of bacteria to vaginal epithelial cells at various times in the menstrual cycle. Infect Immun 32, 194-197.

Swidsinski, A., Mendling, W., Loening-Baucke, V., Ladhoff, A., Swidsinski, W., Hale, L. P. \& Lochs, H. (2005). Adherent biofilms in bacterial vaginosis. Obstet Gynecol 106, 1013-1023.

Swidsinski, A., Mendling, W., Loening-Baucke, V., Swidsinski, S., Dorffel, Y., Scholze, J., Lochs, H. \& Verstraelen, H. (2008). An adherent Gardnerella vaginalis biofilm persists on the vaginal epithelium after standard therapy with oral metronidazole. Am J Obstet Gynecol 198, 97.e1-6.

Verstraelen, H., Verhelst, R., Claeys, G., Temmerman, M. \& Vaneechoutte, M. (2004). Culture-independent analysis of vaginal microflora: the unrecognized association of Atopobium vaginae with bacterial vaginosis. Am J Obstet Gynecol 191, 1130-1132.

Zhou, X., Bent, S. J., Schneider, M. G., Davis, C. C., Islam, M. R. \& Forney, L. J. (2004). Characterization of vaginal microbial communities in adult healthy women using cultivation-independent methods. Microbiology 150, 2565-2573.

Edited by: R. J. Palmer 